\title{
Hair Lead Bio-Monitoring Among School Children in the Province of Cavite, Philippines
}

\author{
${ }^{1}$ Janet P. Macawile and ${ }^{2}$ Glenn L. Sia Su \\ ${ }^{1}$ Department of Biology, De La Salle University, Dasmarinas, Philippines \\ ${ }^{2}$ Department of Biology, University of the Philippines, Manila, Philippines
}

Received 2012-06-08, Revised 2013-01-03; Accepted 2013-01-22

\begin{abstract}
Airborne lead is one of the pressing environmental problems that cause neuropsychological impairments to people who are exposed to it. In assessing people's exposure to airborne lead, bio-monitoring techniques has been used as an indicator of chemical exposure. This study aims to determine the hair lead concentrations among school children in the province of Cavite and compare the hair lead concentrations of the school children living and studying in the urban and rural areas of the province of Cavite, Philippines. Consenting public and private school children of the municipalities of Bacoor and Alfonso were involved in the study. Hair strands were obtained from each student and analyzed for lead concentrations. Results of hair lead concentrations were compared for significant differences between the public and private schools in both areas using the $t$ test under the significance level of $p<0.05$. A total of 922 consenting school children participated in this study. The hair lead concentrations (mean \pm SD) of all school children surveyed was $0.2814 \pm 0.1245$ ppm. Hair lead concentrations of children studying in public schools were higher relative to those in private schools. School children residing in the urban areas had higher hair lead concentrations compared with those residing in the rural areas. Hair lead concentrations of school children living in urban and rural areas and those studying in private and public schools in Bacoor and Alfonso were found to be significantly different $(t=9.096$ and $t=6.867$, respectively; $p<0.05$ ). Findings indicate that school children are exposed to airborne lead.
\end{abstract}

Keywords: Lead, Hair Bio-Monitoring, Public Health

\section{INTRODUCTION}

Airborne lead is one of the pressing environmental problems, together with air pollution, that confront us. Airborne lead causes neuropsychological impairments to people who are chronically exposed to it. Airborne lead is a global health problem that greatly affects millions of lives, because it is exacerbated by the continuous emissions generated from motor vehicles, industries and the domestic sector.

Airborne lead in Metro Manila, Philippines, has been reported to be emitted excessively due to the accelerating growth rate of vehicle density. The increasing number of smoke belching vehicles running through the streets is identified as one of the significant contributor to the occurrences of air pollution (Lin et al., 2006). The air pollution dilemma is not just limited in Metro Manila alone but also in other cities of the country, such as the province of Cavite.

Amidst the economic development, the vast increase in population and the buildup of vehicular density, a correspondingly escalating problem of air pollution causing long-lasting and expensive health problems to people who are exposed to the pollutants that taint our atmosphere is a growing concern. The possibility of determining the significant effect of air pollution, particularly on airborne lead, over the young populace, particularly among the school children in the province of Cavite, can help bridge the gap on the understanding of the importance and complexity of the relationship between

Corresponding Author: Glenn L., Department of Biology, University of the Philippines, Manila, Philippines 
environment and human health. The deteriorating air quality poses numerous impacts to public health, particularly among the young, as the presence of the pollutants in the atmosphere may result to a subtle biochemical and physiological change (Yang et al., 2008) to an aggravating respiratory and cardiac condition (Prisby et al., 2008) and as worse as cancer (Parent et al., 2007).

Children are particularly sensitive to the effects of air pollution, particularly airborne lead (Cory-Schlecta and Schaumburg, 2000). A previous study (Walkowiak et al., 1998) indicated that children who are exposed to airborne lead severely affect their cognitive and motor functioning. The school children's well-being from their day-to-day exposure to pollution while traversing the streets is of utmost concern. To date, there had been limited studies that dealt with determining the health conditions of children on their exposures to environmental pollutants. In assessing people's exposure to airborne lead, biomonitoring techniques have been used as an indicator of chemical exposure. According to Rosborg et al. (2003), hair bio-monitoring is an alternative technique in the determination of long-term environmental pollutants, such as airborne lead exposure.

With these concern, this study aims to determine the trace lead status of school children and determine whether socio-demographic, Body Mass Index (BMI), mode of transportation to school and location greatly influence the occurrence of hair lead concentrations of school children. The result of this study is vital, as it provides baseline information on the trace lead status and the factors that contribute to the exposure of the children to airborne lead. Likewise, this study is significant because it is of great concern to all, especially because each one of us is exposed to the problem of air pollution, particularly airborne lead. This problem is a perennial problem that remains at the forefront of policy debates today. In this regard, the result generated in this study could bring awareness and realization among the concerned sectors and departments of the government to concretize necessary actions against the air pollution dilemma, particularly to airborne lead exposure, as it may influence the health of the young populace in the country.

\section{MATERIALS AND METHODS}

Cavite is a province in the Philippines that is situated in the CALABARZON region in Luzon and just $30 \mathrm{~km}$ south of Manila. It is surrounded by the province of Laguna to the east and the province of Batangas to the south. Among the cities and municipalities in the province of Cavite, two municipalities were selected. The municipality of Bacoor represented an environment that is urban and is congested with a traffic volume of $\geq 20 \%$ and high vehicular density, whereas the municipality of Alfonso represented an environment that is rural and is uncongested with a traffic volume of $<20 \%$ and low vehicular density. The municipality of Bacoor is situated $16 \mathrm{~km}$ away from Manila and is recognized as a first-class urban municipality in the province, whereas the municipality of Alfonso is situated at the southwestern upland portion of the province of Cavite.

Both public and private schools of the municipalities of Bacoor and Alfonso were selected as the study sites. The study subjects were composed of preparatory, primary and secondary school children. The selection of the study subjects were based on an inclusion-exclusion criterion set by the investigators. Respondents who expressed their willingness to join the study, provided their informed consent, provided hair samples and were willing to be interviewed were included in the study. The approval of the conduct of this study was secured from the ethics committee of the institution where the author is connected and from the public and private school administrators. Letters of informed consent were sent to the parents of the school children who volunteered and the parents and the school children were informed of the objectives of the investigation. All subjects and their parents gave their informed consent.

The interview schedule used in the study looked into the socio-demographic factors such as age, gender and educational level. In the survey, the schedule looked into the children's mode of traveling from home to school to home and the length of their travel time. The weight and height of the participating school children were determined through anthropometric measurements. The BMI was determined using the weight for height and height for age indices using the World Health Organization's Standards for Asian Populations.

Approximately $3 \mathrm{~cm}(0.5 \mathrm{~g})$ of hair strands obtained from the proximal end in the occipital region was collected. Hair samples were placed in a carefully sealed plastic bag and were labeled. All specimens were stored in a cool, dry, ventilated environment until delivered to the laboratory. In the laboratory, hair samples were placed in amber bottles and a 5:1 ratio of nitric acid and hydrochloric acid were added and set aside overnight for acid digestion. Digested hair was filtered and transferred to polyethylene bottles and diluted with distilled water. Analyses for lead concentrations were read using the Atomic Absorption 
Spectrophotometry Model AA-6300 (Shimadzu Scientific Instruments, Inc., Nakagyoku, Japan). Appropriate controls and standards and calibration curves were prepared for the variable to be tested and samples were read three times.

Results of the hair lead concentrations were analyzed for significant differences between the public and private schools in both the municipalities using the $t$ test. Analysis of variance was used to evaluate whether the factors (age, education level, mode of traveling to home to school to home, length of travel time to home to school and BMI) and the t test used to evaluate the factors (gender, school and location) were significantly different from the metal hair concentrations of the school children examined. A test with a $p<0.05$ indicates that all statistical analyses are significant. All statistical analyses were performed using the Statistical Package for Social Sciences software.

\section{RESULTS}

A total of 922 school children gave their informed consent and their parents' informed consent. Of this total number of school children who participated in the study, there were 651 elementary and 271 high school students. About 500 school children lived in the municipality of Bacoor, whereas 422 school children lived in the municipality of Alfonso. There were 559 (60.63\%) girls and $363(39.37 \%)$ boys. The age (mean \pm SD) of the respondents was $10 \pm 3$ years. Interviews with the parents and the school children revealed that about $37.3 \%$ of the school children who participated in the study commute by walking from their homes to their schools. Most of those respondents who travel to school by taking transportation indicated that they ride non-air-conditioned vehicles $(53.90 \%)$, whereas about $8.57 \%$ indicated that they ride air-conditioned vehicles going to their schools. The time traveled by most students as indicated from the survey ranges from 1 to $120 \mathrm{~min}$. Table 1 presents the sociodemographic and personal information of the respondents.

Table 2 presents the comparison of the metal levels in the hair of the school children between the municipalities of Bacoor and Alfonso. The hair lead concentration (mean $\pm \mathrm{SD}$ ) of the school children was $0.2814 \pm 0.1245 \mathrm{ppm}$. School children residing in the municipality of Bacoor showed a higher hair lead concentration (mean \pm SD) with $0.3079 \pm 0.1442 \mathrm{ppm}$ compared with those school children residing in the municipality of Alfonso with a hair lead concentration (mean \pm SD) of $0.2499 \pm 0.0863 \mathrm{ppm}$. The hair lead concentrations (mean \pm SD) of the school children studying in public schools were relatively higher $(0.3044 \pm 0.1081 \mathrm{ppm})$ than those school children studying in private schools $(0.2259 \pm 0.1428 \mathrm{ppm})$.
Table 1. Socio-demographic profile of the school children in the province of Cavite

\begin{tabular}{lcc}
\hline Socio-demographic Factors & Frequency (n) & Percentage \\
\hline Location: & 500 & \\
Bacoor & 422 & 54.23 \\
Alfonso & & 45.77 \\
Type of school & 500 & \\
Public & 422 & 54.23 \\
Private & & 45.77 \\
Gender & 363 & \\
Male & 559 & 39.37 \\
Female & & 60.63 \\
Education level & 651 & \\
Elementary & 271 & 70.61 \\
High school & & 29.39 \\
Mode of going to school & 344 & \\
Walking & 497 & 37.31 \\
Non-air-conditioned vehicle & 79 & 53.90 \\
Air-conditioned vehicle & 8.57 \\
Length of travel time from home to school & \\
1 min & 2 & 0.22 \\
5 min & 218 & 23.64 \\
10 min & 221 & 23.97 \\
15 min & 123 & 13.34 \\
30 min & 80 & 8.68 \\
120 min & 1 & 0.11 \\
\hline
\end{tabular}

Table 2. Comparison of the hair lead concentrations of public and private school children living in Bacoor and Alfonso

\begin{tabular}{lcll}
\hline Variables & $\mathrm{Pb}($ mean $\pm \mathrm{SD})$ & $\mathrm{t}$ & $\mathrm{p}$ \\
\hline Location & $0.2814 \pm 0.1245$ & 6.867 & $0.000^{*}$ \\
Bacoor & $0.3079 \pm 0.1442$ & & \\
Alfonso & $0.2499 \pm 0.0863$ & & \\
Type of school & $0.2814 \pm 0.1245$ & 9.096 & $0.000^{*}$ \\
Public & $0.3044 \pm 0.1081$ & & \\
Bacoor & $0.3463 \pm 0.1045$ & & \\
Alfonso & $0.2585 \pm 0.9232$ & & \\
Private & $0.2259 \pm 0.1428$ & & \\
Bacoor & $0.2262 \pm 0.1792$ & & \\
Alfonso & $0.2246 \pm 0.0602$ & & \\
\hline
\end{tabular}
" $\mathrm{p}<0.05$.

Table 3. Hair lead concentration and socio-demographic factors of school children in the municipalities of Bacoor and Alfonso

\begin{tabular}{llrl}
\hline Socio-demographic & & & \\
Factors & Mean $\pm \mathrm{SD}$ & $\mathrm{F}$ & $\mathrm{p}$ \\
\hline Age & $0.2810 \pm 0.12446$ & 5.274 & $0.000^{*}$ \\
Level of education & $0.2814 \pm 0.12455$ & 13.020 & $0.000^{*}$ \\
BMI & $0.2814 \pm 0.12455$ & 1.532 & $0.000^{*}$ \\
Mode of transportation & $0.2810 \pm 0.12446$ & 7.131 & $0.000^{*}$ \\
Length of travel time & $0.2810 \pm 0.12446$ & 1.912 & $0.002^{*}$ \\
from home to school & & & \\
\hline
\end{tabular}

" $\mathrm{p}<0.05$, ANOVA 
Public school children residing in the municipality of Bacoor likewise have shown higher hair lead concentrations (mean $\pm \mathrm{SD}, \quad 0.3463 \pm 0.1045 \mathrm{ppm}$ ) compared with those public school children who reside in the municipality of Alfonso $(0.2585 \pm 0.9232 \mathrm{ppm})$. Similarly, private school children that reside in the municipality of Bacoor showed higher hair lead concentration of $0.2262 \pm 0.1792 \mathrm{ppm}$ (mean \pm SD) as compared with those residing in the municipality of Alfonso with $0.2246 \pm 0.0602 \mathrm{ppm}$.

Table 3 presents the socio-demographic factors and the metal levels in the hairs of the school children examined. Results showed that the young school children (3-6 years old) living in the municipality of Bacoor had the highest hair lead concentration of $0.36027 \pm 0.0452 \mathrm{ppm}$ (mean \pm SD) compared with those school children ages 15-19 years with a hair lead concentration of $0.3434 \pm 0.084$ ppm (mean \pm SD). Elementary school children had the a higher hair lead concentration of $0.3463 \pm 0.1045 \mathrm{ppm}($ mean \pm SD) as compared with those in the high school level with $0.2262 \pm 0.1792 \mathrm{ppm}$. Similar results were likewise observed among those school children residing in the municipality of Alfonso wherein the hair lead concentration of the elementary levels (mean $\pm \mathrm{SD}$, $0.2585 \pm 0.0923 \mathrm{ppm}$ ) was slightly higher than those in the high school level (mean \pm SD, 0.2254 $\pm 0.0605 \mathrm{ppm}$ ). Female school children who were classified as underweight $(0.3068 \pm 0.1124 \mathrm{ppm})$ through their BMI, using the World Health Organization standards for Asian populations, showed higher hair lead concentration (mean \pm SD) as compared with the male school children $(0.2925 \pm 0.1111 \mathrm{ppm})$ across both municipalities where the school children reside. The underweight school children had slightly higher hair lead concentration (mean \pm SD) as compared with the normal weighted male $(0.2671 \pm 0.1170$ ppm) and female $(0.2657 \pm 0.1175 \mathrm{ppm})$ school children.

Children who studied in the municipality of Bacoor and who walk from their homes to their school had lower hair lead concentration of $0.2633 \pm 0.1117 \mathrm{ppm}$ (mean \pm SD) as compared with those who rode non-air-conditioned vehicles $(0.4381 \pm 0.0669 \mathrm{ppm})$ as opposed to those who rode air-conditioned vehicles $(0.3657 \pm 0.1139 \mathrm{ppm})$. Similar results were likewise obtained among those children who studied in the municipality of Alfonso who walk from their homes to school $(0.2674 \pm 0.0822 \mathrm{ppm})$ as opposed to those who rode non-air-conditioned vehicles $(0.2764 \pm 0.0878 \mathrm{ppm})$. As the children commute from their homes to their schools, school children who traveled over a span of 35-60 min had the highest hair lead concentration (mean \pm SD) of $0.3320 \pm 0.1355 \mathrm{ppm}$ in Bacoor and $0.4595 \pm 0.0624 \mathrm{ppm}$ in Alfonso. The male school children in Bacoor had a higher hair lead concentration (mean \pm $\mathrm{SD)}$ of $0.3133 \pm 0.1367 \mathrm{ppm}$ as compared with the female school children with $0.3046 \pm 0.1487 \mathrm{ppm}$. Whereas in the school children in Alfonso, the female school children had higher hair lead concentration (mean \pm SD) of $0.2549 \pm 0.08008 \mathrm{ppm}$ compared with the male school children with $0.2426 \pm 0.0941 \mathrm{ppm}$.

Results of this study has shown in Table 3 that the socio-demographic factors age, educational level, BMI, mode of transportation and length of traveling time from the school children's home to their school in relation to their metal concentration in their hair were significantly different $(\mathrm{p}<0.05)$ from each other except for gender $(\mathrm{t}=$ $0.678 ; \mathrm{p}>0.05)$.

\section{DISCUSSION}

This study was cross-sectional in nature. Children who were studying in schools are those who are represented in the study. Results of the study has shown that those school children who were studying in public schools and in the municipality of Bacoor were found to have higher metal concentrations in their hairs as compared with those who were studying in private schools and those residing in the municipality of Alfonso. As a basis of our observations, generally, the classrooms of those students who were studying in private schools in both municipalities were fully air-conditioned and students were confined in their respective classrooms as compared with those studying in public schools who had their class activities done outside of their classrooms and had classrooms that were always open, hence, increasing the chances of exposure to the vehicles that traverse the streets where the schools are situated. Likewise, the result of our study has shown that children who were residing in the area where there is high vehicular density had higher lead concentrations in the hair as compared with those who reside in rural area where there is low vehicular density. Our results also showed that the hair lead concentrations were higher among those school children who were riding non-air-conditioned public utility vehicles, unlike those who ride air-conditioned public utility vehicles. Longer traveling time from the school children's home to school has shown a significant influence on the hair lead concentrations of the children; as the children commute longer, higher hair lead concentrations were evident. It is likely that riding the non-air-conditioned public utility vehicles and commuting for longer time from their homes to school and vice versa increase the chances of the students to 
be exposed to the emissions in the polluted area. A study by Zaitseva et al. (1998) showed that hair lead concentrations were higher in polluted areas as compared with those areas with lower pollution.

The result of our study has shown that elementary school children had higher metal concentrations in their hair as compared with those in high school level. This finding may likely be attributed to the innate behavior of the elementary school children who tend to explore everything that they see around them, whether this may be at school or at home. The behavior of children to explore things around them makes them more susceptible to possible sources of lead in the environment. The usual behavior of the children, touching and tasting anything in the environment, may increase the chances of elementary school children to expose themselves to the different sources of lead that may be present in their environment. Our interviews with high school students have indicated that they mostly use their handkerchiefs to protect themselves from vehicular emissions as they traverse the streets from their homes to their schools and vice versa. This particular behavior shows that high school students have become conscious of the harmful emission generated by vehicles and they tend to reduce their exposure by protecting themselves. This finding is likewise supported by Esan et al. (2004), where they indicated that children who belong to the higher education group tend to be more conscious of their health needs and practice good hygiene better because they have become well informed due to their increasing level of literacy and the positive social changes that they get from practicing good hygiene from meeting their health needs. It is also likely that, as in a study by Bao et al. (2009), they have indicated that children were the most susceptible to heavy metal exposure as they absorb more of the heavy metal and excrete less as compared with the adults. Our results also showed that the males' and females' hair lead concentrations were not significantly different from each other. Similar findings of Caroli et al. (1992) support our findings.

Our findings likewise have shown that the hair lead concentrations were higher among underweight children as compared with normal weight children. A study (Walkowiak et al., 1998) presented that lead accumulation tends to be higher among underweight children mainly because of the nutrient deficiency that these children may have in their diets. Our study has also shown a high hair lead concentration among overweight children. A study (Padilla et al., 2010) presented that, in overweight individuals, lead accumulation may indirectly induce oxidative stress, consequently stimulating lipogenesis at the expense of energy production.

\section{CONCLUSION}

Results of our study have shown hair lead concentrations in school children examined in both municipalities. Exposure to polluted environments increases the chances of the school children to have higher hair lead concentrations. Higher hair lead concentrations were evident among those school children who were residing in an area where there is high vehicular density, who rode non-air-conditioned public utility vehicles, who traversed through the streets with longer traveling times, who were young and who were underweight. Continuous monitoring on the welfare of the school children against airborne lead is necessary to safeguard them from the possible dangers that this heavy metal may bring.

\section{ACKNOWLEDGEMENT}

We would like to express our sincerest gratitude to the all those who have assisted and supported this study.

\section{REFERENCES}

Bao, Q.S., C.Y. Lu, H. Song, M. Wong and W. Ling et al., 2009. Behavioral development of school-aged children who live around a multi-metal sulphide mine in Guangdong province, China: A cross-sectional study. BMC Public Health, 9: 217.

Caroli, S., O. Senofonte, N. Violante, I. Fornarelli and A. Powar, 1992. Assessment of reference values for elements in hair of urban normal subjects. Michrochem. J., 46: 174-183. DOI: 10.1016/0026265X(92)90035-2

Cory-Schlecta, D.A. and H.H. Schaumburg, 2000. Lead Inorganic. In: Experimental and Clinical Neurotoxicology, Spencer, P.S., H.H. Schaumburg and A.C. Ludolph (Eds.), Oxford University Press, USA., ISBN-10: 0195084772, pp: 708-720.

Esan, T.A., A.O. Olusile, P.A. Akeredulo and A.O. Esan, 2004. Socio-demographic factors and endulism: The Nigerian experience. BMC Oral Health.

Lin, C.W., S.J. Lu and K.S. Lin, 2006. Test emission characteristics of motorcycles in Central Taiwan. Sci. Total Environ., 368: 435-43. DOI: 10.1016/j.scitotenv.2006.03.032

Padilla, M.A., M. Elobeid, D.M. Ruden and D.B. Allison, 2010. An examination of the association of selected toxic metals with total and central obesity indices: NHANES 99-02. Int. J. Environ. Res. Public Health, 7: 3332-3347. DOI: 10.3390/ijerph7093332 
Parent, M.E., M.C. Rousseau, P. Boffeta, A. Cohen and J. Siemiatycki, 2007. Exposure to diesel and gasoline engine emissions and the risk of lung cancer. Am. J. Epidemiol., 165: 53-62. DOI: 10.1093/aje/kwj343

Prisby, R.D., J. Muller-Delp, M.D. Delp and T.R. Nurkiewicz, 2008. Age, gender and hormonal status modulate the vascular toxicity of the diesel exhaust extract phenanthraquinone. J. Toxicol. Environ. Health Part A, 71: 464-70. DOI: $10.1080 / 15287390701839349$

Rosborg, I., B. Nihlgard and L. Gerhardsson, 2003. Hair element concentrations in females in one acid and one alkaline area in southern Sweden. Ambio, 32: 440446. DOI: $10.1639 / 0044-$
Walkowiak, J., L. Altmann, U. Kramer, K. Sveinsson and M. Turfeld et al., 1998. Cognitive and sensorimotor functions in 6-year old children in relation to lead and mercury levels: Adjustment for intelligence and contrast sensitivity in computerized testing. Neurotoxicol. Teratol., 20: 511-521. DOI: 10.1016/S0892-0362(98)00010-5

Yang, I.A., K.M. Fong, P.V. Zimmerman, S.T. Holgate and J.W. Holloway, 2008. Genetic susceptibility to the respiratory effects of air pollution. Thorax, 63: 555563. PMID: 18511640

Zaitseva, N.V., T.S. Tyrykina, M.A. Zemylanova, O.V. Dolgich and P.Z. Shur, 1998. Evaluation of gasoline lead influence on high risk groups in Perm, Russia population. Epidemiology, 9: S140-S140. 